The time needed to fix the ink is even shorter than with Bouin's solution, being less than 10 seconds, and the staining effect obtained with Bouin's solution, sometimes unwanted, is avoided. The solution must be changed weekly.

No microscopical artefacts have been seen and no tissue damage at the histochemical or immunohistochemical level have been revealed after four months of routine use. The solution has now been permanently introduced in our dissection room.

$$
\begin{array}{r}
\text { A SALERNO } \\
\text { R TRENT } \\
\text { P J JACKSON } \\
\text { M G COOK } \\
\text { Histopathology Department, } \\
\text { Royal Surrey County Hospital, } \\
\text { Egerton Road, } \\
\text { Guildford GU2 } 5 X X
\end{array}
$$

1 Bogomoletz WV, Davies JD. Examination of breast specimens. London: ACP/BMA. ACP breast specimens. London:
Broadsheet 116: July 1987.

2 Stuart J, Schnitt MD. Specimen processing. In: Tavassoli FA, ed. Pathology of the breast. Norwalk, CT: Appleton and Lang, 1993:63-78.

3 Bouin P. Etudes sur l'évolution normale et l'involution du tube séminifére, I: modifications régressive du processus spermatogénétiques provoquées expérimentalement. Arch Anat Microsc 1897;1:225-62.

4 Chan KW, Lui I, Chung WB. Marking planes of surgical excision with a mixture of India ink and acetone [letter]. $\mathcal{f}$ Clin Pathol 1989;42: 893.

5 Wyman JF, Serve PM, Hobson DW, Lanfong $\mathrm{HD}$, Uddin DE. Acute toxicity, distribution and metabolism of 2,4,6-trinitrophenol (pictric acid) in Fisher 344 rats. $\mathcal{F}$ Toxicol Environ Health 1992;37:313-27.

\section{Necrobiotic granulomas of the urogenital system}

We agree with Dr Agel ${ }^{1}$ that the granulomatous tissue response associated with diathermy and laser treatment warrants wider diagnostic recognition. Unfortunately, however, Dr Agel appears to have overlooked our own contribution ${ }^{2}$ to the nature and origin of diathermy pigment in such specimens. We also believe that the potential biohazardous nature of diathermy pigment, because of the nature of its metallic composition, is poorly appreciated and deserves greater emphasis.

In our study 14 cases of postsurgical granulomatous inflammation within the urinary tract were investigated using electron microscopy and energy dispersive analysis of $x$ rays (EDAX). The findings were then correlated with the composition of diathermy instruments which had also been subjected to metallurgical analysis. The brown staining material, observed on light microscopy by ourselves and Dr Agel, appeared amorphous ultrastructurally and was found to contain iron, calcium, aluminium, phosphorous, sulphur, and chlorine by EDAX. This material was interpreted as necrotic tissue with absorbed metallic salts from the surrounding body fluids. By contrast, darker particulate material present appeared electron dense and contained variable combinations of three different groups of elements. These comprised pure tungsten, from tungsten wire cutting loops, copper, zinc, nickel, manganese, and iron from nickel silver coagulation "roller balls" and iron, chromium, nickel, manganese, molybdenium, copper, and vanadium from the stainless steel supporting wires. Whereas tungsten is probably biologically inert, evidence indicates that nickel, chromium, copper, and zinc are immunogenic. Also, in certain circumstances, both nickel and chromium can be carcinogenic. Consequently, on the basis of these observations, we have suggested that it is probably advisable to discontinue the use of nickel, chromium, zinc, and copper in the manufacture of diathermy electrodes. A strengthened tungsten electrode, possibly in a ceramic mount, would seem to offer a more biocompatible alternative.

It would also appear desirable that the granulomatous response following later treatment is subjected to a similar, extensive microanalytical study. Aluminium oxide, possibly derived from the laser housing, has been found in one case.

D SLATER Department of Histopathology,
Rotherham Hospitals NHS Trust, Moorgate Road,
Rotherham S60 2UD

L HENRY

Department of Pathology, University of Sheffield, University of Sheffield,
Royal Hallamshire Hospital, Sheffield

1 Agel NM. Necrobiotic granulomas of the urogenital system. F Clin Pathol 1995;48:185.

2 Henry L, Wagner B, Faulkner MK, Slater DN, Ansell ID. Metal deposition in post-surgical granulomas of the urinary tract. Histopathology granulomas of the

3 Thurrell W, Reid P, Kennedy A, Smith JHF. Necrotising granulomas of the peritoneum. Histopathology 1991;18:190.

\section{Dr Agel comments:}

I thank Dr Slater and Professor Henry for their comment on my letter. ${ }^{1}$ My letter described the presence of "diathermy pigment" in most of the granulomas found in uteri and urinary bladders following either laser or diathermy resection. The recognition of such a pigment should be of help to diagnostic histopathologists when investigating granulomatous conditions of the urogenital system. It was not my intention to discuss the nature of the pigment; such discussion will appear in a detailed paper which describes our cases where the work of Henry et $a l^{2}$ will be appropriately quoted.

\section{Audit of tumour pathology reviewed by a regional oncology centre}

I was very encouraged to read of the audit of tumour histopathology referred by a district general hospital and received by the regional oncology centre. ${ }^{1}$ It includes my own areas of difficulty, lymphomas, sarcomas and grading of ovarian epithelial neoplasms. I also note a statement in the introduction, which should perhaps be given greater emphasis, that a copy of the pathological findings is sent back from the oncology centre to the district general hospital.

Patients from our hospital are referred to several specialist oncology and radiotherapy centres, and slides and reports are sent. Long before the advent of any formal external quality assessment schemes, I have found a copy of the reviewing pathologist's report to be an extremely helpful, routine form of quality control. It enables any major or minor diagnostic discrepancies to be considered, reveals what classification is being used and suggests what prognostic histological features should be mentioned. There is a second important practical consideration. The patient will return to the district hospital for follow up and possible further biopsies. If there is a significant discrepancy between the report of the referring pathologist and the diagnosis given back to the clinician, the potential exists for future confusion unless the pathologist is aware of it.

Over the years I have found that some pathology departments are extremely punc- tilious about sending their reports. Some rely on a single conscientious individual who may leave and occasional hospitals cannot seem to manage it with any degree of reliability.

Most departments are now computerised. I would like to make a plea that it becomes routine practice that referral centres generate an extra copy of the report on all reviewed histology for dispatch to the referring histopathology department. This practice is much less contrived than external quality assessment schemes, and is both courteous and useful to the referring pathologist.

K THOMAS
Whipps Cross Hospital,
Whipps Cross Road,
Leytonstone,
London E11 1NR

1 Preston RJ, Wells S, Bisset DL, Banerjee SS, Harris M. Audit of tumour pathology reviewed by a regional oncology centre. $\mathcal{F}$ Clin Pathol 1995;48:245-9.

\section{Book reviews}

Atlas of Gynecologic Pathology. 2nd edn. JD Woodruff, TL Angtuaco, TH Parmley. (Pp 325; \$170.50.) Raven Press. 1993. ISBN 0-7817-0056-6.

The objective of this atlas, as stated in the preface to the first edition, is to present gynaecological pathology in broad terms giving the novice a general introduction. The text on the back flap claims that the atlas is an essential diagnostic tool for every pathologist and gynaecologist. Does this atlas achieve these goals which appear prima facie to be mutually incompatible?

A strong correlation between clinical and pathological appearances is achieved in this work. Embryological development and normal histology are described at the beginning of the chapters. This book contains clinical pictures, many colour photomicrographs and also, new to this edition, many radiological illustrations. Annotated drawings accompany photomicrographs and radiological images to facilitate their interpretation. The text on the back flap mentions state-of-the-art electron micrographs; I did not find any, although a few photomicrographs of immunohistochemical stains are included.

It is a pleasure to browse through this atlas as the photomicrographs are almost all of good quality. The text is generally well integrated with the pictures. The balance of text and numbers of photomicrographs follows the authors' stated objective. Nine pages including 20 photomicrographs are devoted to placental development. Borderline serous and mucinous ovarian tumours are dealt with briefly and the accompanying text does not clearly indicate the histopathological criteria of borderline malignancy. The absence of rare but well described lesions and general lack of histopathological differential diagnostic considerations limits the usefulness of this atlas for the diagnostic histopathologist.

This book does, I think, achieve the stated aim of an introduction to gynaecological pathology though some parts of the text could well lead to confusion. To achieve the prime object has led, as the authors' accept, to selection of material. Though the pictures are delightful, I cannot recommend this atlas as a histopathology bench book.

M J SWORN 